\title{
Mortality at Old Age in the Nordic Countries ${ }^{1}$
}

\author{
VÄINÖ KANNISTO \\ Consultant \\ Centro de Estudos Demográficos \\ Lisbon, Portugal
}

\section{Introduction}

The mortality of the aged has recently been increasingly the focus of studies in Finland, motivated by the high death rates of middle-aged and older men observed there. Naturally, comparisons with the other Nordic countries are frequently made. It was, after all, a comparison with Swedish data that made it possible to first recognize the extent of the problem in Finland and to identify the causes of death responsible for it (Kannisto, 1945). In recent years the mortality of the elderly has declined both in the Nordic area and in various other countries in an unprecedented manner convincing observers that it is not an immovable force nor a factor capable of showing only pale reflections of the health benefits bestowed upon the young and the middle-aged.

The present study is intended as a contribution to the knowledge of this area of public health by concentrating on the oldest age groups which have received relatively less attention, perhaps due to certain weaknesses which affected the basic population data at these ages prior to 1950 . We shall examine the development of mortality at ages above 80 years in the Nordic countries since 1950 and try to ensure data reliability by using the method of extinct cohorts which generates its own data on population stocks. The study is expected to complement another one, under preparation by Martelin and Valkonen, which covers the same countries but focuses on the ages from 60 to 84 years. The development of the aged population in four Nordic countries has recently been described by Valkonen and Nikander (1987).

\section{The method}

The present study uses the method of extinct generations which was pioneered by Vincent in 1951. The procedure is to cumulate the deaths of each birth cohort from the oldest towards the younger ones thus obtaining data on population stocks which are directly related to deaths and therefore often more reliable than independently collected population data such as derived from a census. It follows that the method is in principle valid only for already extinct generations - hence its name.

We have, however, extended the method to living cohorts by using the most recent population figure as the base in each cohort and cumulating it backwards down

I I thank the National Statistical Offices of the five Nordic countries for their help in making the data available to me, and Ms. Tuija Martelin of the Department of Sosiology, University of Helsinki, for additional documentation. 
to age 80 with data on deaths. This can be considered fully satisfactory in view of the proven high accuracy of the Nordic population registers. This fact actually makes the method of extinct generations redundant because the data on the living and the dead are supposed to be fully interlocking. In the present context, however, this cannot be guaranteed for the early periods and was manifestly not the case with Finnish population data of the 1920s and 1930s. See e.g. Kolari (1980) and Pitkänen (1986).

The method of extinct generations, because it is based on mortality histories of birth cohorts, requires data cross-tabulated by single years of age and the year of birth. Such data are available for Denmark, Finland, and Sweden. ${ }^{2}$ The data for Iceland are given by age alone and needed to be allocated to birth cohorts. The data for Norway are by year of birth and when this is subtracted from the year of death, we have what we shall call "cohort age», i.e. the age the persons of the cohort reach that year unless they die before their birthday. For the construction of cohort mortality histories, the deaths in these two countries were subdivided into the required categories using factors based on the data for Sweden in 1972-84 (Table 1). The difference between the two sets of factors is due to seasonal variation in natality and mortality.

$\mathrm{T} \mathrm{a} \mathrm{b} \mathrm{l} \mathrm{e} \mathrm{1.} \mathrm{Separation} \mathrm{factors} \mathrm{for} \mathrm{construction} \mathrm{of} \mathrm{cohort} \mathrm{mortality} \mathrm{histories.}$

A. Age known, cohort unknown

Age $\quad \begin{gathered}\text { Proportion who died } \\ \text { after birthday } \\ \text { (younger cohort) }\end{gathered}$

$\begin{array}{rr}80-86 & .50 \\ 87-91 & .51 \\ 92-99 & .52 \\ 100- & .53\end{array}$

B. Cohort known, age unknown

$\begin{array}{cc}\begin{array}{l}\text { Cohort } \\ \text { age }\end{array} & \begin{array}{c}\text { Proportion who died } \\ \text { before birthday } \\ \text { (younger age) }\end{array} \\ 80-81 & .50 \\ 82-84 & .51 \\ 85-88 & .52 \\ 89-91 & .53 \\ 92-93 & .54 \\ 94-95 & .55 \\ 96 & .56 \\ 97-98 & .57 \\ 99 & .58 \\ 100- & .59\end{array}$

The deaths in Denmark have been published by single years of age only up to 99 years, and since 1979 up to 98 years. As tabulations for ages 100 and over were made available to us for the years 1970-78, we used them as a basis for allocating the deaths of the other periods to individual birth cohorts. Errors resulting from this estimation are negligible regarding mortality at ages below 90 but might be of some importance in the age group 95 and over in which the estimated element in both the numerator and the denominator amounts to about 13 percent and the two errors are not necessarily concurrent. Above age 100 , the imprecision would be unacceptably large. This situation has placed some constraints on the study and in order to maintain comparability between the countries we have limited it to the age span of $80-99$ years except for some general results calculated for the population of 80 years and over as a whole.

2 The Swedish data for $1921-23$ and 1926 are by age only and we split them between the cohorts in proportions found for the other years of the $1920-28$ period. 
Mortality histories for each sex in Denmark, Finland, Norway, and Sweden were constructed for cohorts 1840-1904 from age 80 on, and for earlier cohorts from the age they were on 1 January 1920 . The coverage for Iceland was reduced by the fact that we have data for Iceland only since 1961 .

Cohort mortality histories yield probabilities of dying at specified ages $\left(\mathrm{q}_{\mathrm{x}}\right)$. We converted these into central death rates $\left(\mathrm{m}_{\mathrm{x}}\right)$ for 5 -year and wider age groups using as age standards the male and female stationary populations corresponding to the Norwegian life table 1982-83. Sex ratios of mortality were calculated by applying the male and female age-specific death rates to the female age standard. Probabilities of surviving from 80 to 100 years of age $\left.{ }_{20} \mathrm{P}_{80}\right)$ were obtained from single-year probabilities $\mathrm{p}_{\mathrm{x}}=1-\mathrm{q}_{\mathrm{x}}$.

All period rates were calculated quinquennially $(1920-24,1925-29$, etc.) except the last one (1980-83) which covers four years. Averages for longer periods were obtained as unweighted means of quinquennial rates.

It follows from the method used here that there is an overlap in the calendar years ending in 0 or 5 because the deaths in such years before a person's birthday belong to the proceding quinquennial period and only those which occur after the birthday belong to the period so designated. Likewise, the last period in the study, 1980-83, includes the deaths which in 1984 occurred before the person's birthday.

\section{Migration bias}

Vincent's method is perfect for closed populations but subject to systematic errors when there is migration. When a person moves away, the years-at-risk which he lived and survived in his original population will not be credited to it. Similarly, when a person moves into a population and eventually dies, all his past years will be credited to the population he joined. This creates a discrepancy between the numerator and denominator of the death rate. As a consequence, death rates of populations with net out-migration will be artificially increased and those of populations with net in-migration correspondingly lowered. However, migration which occurred at younger ages than those which are being studied or in earlier years than those which are covered, has no effect on the rates.

Because of migration, the method for extinct generations is most adequate at the oldest ages and becomes increasingly uncertain when extended to younger groups. As migration, particularly international, is low at old age, the error is generally considered negligible at ages approaching 100 years. ${ }^{3}$ But how far down can we safely go? Do we run a serious risk at age 80 ?

In the period studied here, the net migration rate in Finland was the following per 1,000 population a year: ${ }^{4}$

$\begin{array}{llll}1921-30 & +0.9 & 1951-60 & -1.6 \\ 1931-40 & +0.8 & 1961-70 & -3.9 \\ 1941-50 & -1.9 & 1971-80 & -0.6\end{array}$

\footnotetext{
${ }^{3}$ Depoid (1973) has published an important study made under the guidance of Vincent which covers the ages 80 and over.

${ }^{4}$ Calculated as the difference between actual and natural population increase according to Suomen Tilastollinen Vuosikirja 1985/86.
} 
Migration is usually heavily concentrated in young ages. Not having data on international migration available, we use the Finnish domestic migration rates per 1,000 population in $1980:^{5}$

$\begin{array}{rrlr}0-14 & 42.6 & 35-44 & 27.7 \\ 15-24 & 74.9 & 45-64 & 13.3 \\ 25-34 & 75.6 & 65- & 7.8\end{array}$

All ages 41.3

We note that the mobility of the over-65-year-old is less than one-fifth of the general average and it is reasonable to assume that the proportion is not higher in international migration. As the highest net rate for all ages was -3.9 per 1,000 , we may conclude that the rate for the elderly did not reach 1 per 1,000 per year in any decade since 1920 and was generally only a fraction of it. Logically, the mobility of those 80 years and over would have been even smaller.

Closer to the age of 100 years international migration virtually stops. In the age group 95 and over the Swedish population register recorded in 1980-84 a net immigration of four persons which amounts to 0.18 per 1,000 population a year, and the Danish register a net immigration of two persons $(0.17$ per 1,000 per year) together with a net decrease of one person through correction.

Assuming now a high alternative, a net migration flow (in or out) of 2 per 1,000 at age 80 , declining linearly to zero at age 100 , we have found that the calculated population data and, inversely, the calculated death rates would have the following errors:

$$
\begin{array}{rr}
\text { at ages } 80-84 & 0.7 \% \\
85-89 & 0.4 \% \\
90-94 & 0.2 \% \\
95- & 0.0 \%
\end{array}
$$

It is therefore concluded that migration has had only a negligible effect on the death rates calculated below.

\section{Period or cohort analysis?}

Although the method of extinct generations requires cohort histories, this still leaves open the choice of presenting the mortality by period or cohort or both.

Examination of our data showed that cohort as such had no discernible effect on mortality. The female 5-year survival ratios of cohorts from age 80 to 85 and from age 85 to 90 showed the following correlation coefficients:

$\begin{array}{ll}\text { Sweden } & \\ 1840-59 & -0.32 \\ 1860-79 & -0.38 \\ 1880-94 & -0.25 \\ \text { Norway } & \\ 1840-59 & -0.04 \\ 1860-79 & -0.44 \\ 1880-94 & -0.10\end{array}$

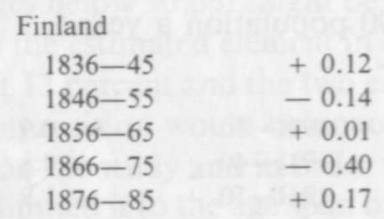

Finland

$1846-55-0.14$

$1856-65+0.01$

$1876-85+0.17$

s Suómen Tilastollinen Vuosikirja 1981. The differences between male and female rates are minor. 
The correlations for males were similar, namely insignificant and generally negative.

In contrast, the same survival ratios in Finland correlated by period as follows:

$\begin{array}{llrr}1921-30 & +0.72 & 1951-60 & +0.56 \\ 1931-40 & +0.77 & 1961-70 & +0.88 \\ 1941-50 & +0.86 & 1971-80 & +0.42\end{array}$

The conclusion is that at least in the countries, times and ages in question, birth cohorts do not display permanent or lasting mortality characteristics of their own. Period events, on the other hand, make themselves immediately felt a wide range of age.

Hobcraft and Gilks (1984) observe on this question: »In all our work on mortality, nuptiality, and fertility we have yet to find an instance where a model without age and period ... components fits at all well. . . . Models also incorporating cohort elements have not often noticeably improved the fit.»

In the following, all results are presented by period.

\section{General development of old age mortality}

The interwar period 1920-39 was a period of stagnation in old age mortality of both sexes during which considerable differences persisted between the countries (Table 2 and Figures 1a, 1b). Norway had by far the lowest rates, Sweden was next and then Denmark, with Finland far higher, particularly regarding men.

The war period caused a sharp rise in the Finnish rates which, however, may be partly an artefact as the mortality statistics of 1936-50 include a sizeable number of persons declared dead by courts - often migrants who may have died overseas long before.

In the 1940s mortality begins a slow decline, sometimes interrupted by reverses. At this time Denmark catches up with Sweden and as the mortality in Norway levels off and even rises, the rates of the three countries converge. Around 1970 the declining trend accelerates in all countries but most of all in Finland whose rates now also tend to converge with the others. In the early 1980 s the death rate of women is almost identical in the four countries while that of men is still highest in Finland. For Iceland we have data beginning only in 1961 and they show rates which for each sex are clearly lower than in the other countries and continue to fall rapidly.

Table 3 highlights the slow decline of mortality until the 1960s and the faster drop thereafter. In almost all cases there was more improvement in the latter period which averages only 17 years than during the previous four decaces. The gains have been greater throughout for women than for men, particularly in the three countries of Scandinavia proper where the mortality of old women has been declining more than twice as rapidly as that of old men.

\section{Age profile of the recent decline}

The great decline in old age mortality since about 1970 has not been uniform for the two sexes nor for the different age groups. See Table 4 and Figure 2.

For men the decline was larger in Finland and slightly smaller in Norway than in the other countries. The gains in Finland and Denmark were larger below age 95 than after it, in Sweden approximately equal at all ages while in Norway male mortality virtually stagnated at $80-84$ years but declined at older ages. 
$\mathrm{T}$ a b 1 e 2. Age-standardized death rates per 1,000 persons aged 80 and over, since 1920 .

Sex

and

year

Denmark

Finland

Iceland

Norway

Sweden

Males

1920-24

192.4

194.7

218.5

1925-29

190.5

216.6

..

164.7

179.1

1930-34

214.3

191.1

226.2

$\ldots$

164.3

181.0

1935-39

180.8

228.4

..

162.0

183.0

1940-44

171.3

204.0

166.2

189.1

1945-49

169.1

1950-54

204.2

...

156.8

175.2

1955-59

166.4

197.2

...

151.2

178.7

1960-64

167.8

1965-69

161.0

196.6

198.8

.

149.7

175.2

169.8

$1970-74$

150.6

187.4

$153.7^{1}$

151.0

166.8

1975-79

169.9

148.0

157.7

160.5

150.2

144.1

154.9

154.9

1980-84

149.6

158.6

120.2

153.5

147.6

155.8

147.1

150.4

Females

1920-24

1925-29

198.1

209.7

..

161.2

181.3

197.8

207.8

..

161.4

181.6

1930-34

202.0

...

160.3

187.3

199.4

217.4

163.6

191.9

1940-44

185.6

207.4

153.3

175.2

193.3

152.7

179.3

1950-54

174.3

198.4

150.2

175.7

178.1

189.6

150.6

165.5

1960-64

164.9

192.5

153.8

$141.5^{1}$

143.9

159.2

151.5

188.2

147.6

149.2

1970-74

135.2

167.7

130.5

139.9

134.2

143.2

104.9

129.2

128.4

1980-84

121.8

130.7

103.3

119.4

120.7

1 1961-64

$\mathrm{T}$ a b l e 3. Percentage decline in mortality at ages 80 and over.

Male

Female

Country

Denmark

Finland

Norway

Sweden

$$
\begin{gathered}
1920-29 \\
\text { to } \\
1960-69
\end{gathered}
$$

15.0

9.1

5.0

9.1
Iceland

$$
\begin{gathered}
1960-69 \\
\text { to } \\
1980-83
\end{gathered}
$$

1 $1961-69$ to $1980-83$
9.0

19.8

$16.7^{1}$

5.9

8.1

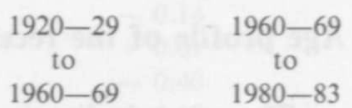

20.1

23.0

31.3

$28.5^{\prime}$

19.8

21.7 
F i g u r e 1 a. Age-standardized death rates, ages 80 and over. Males.

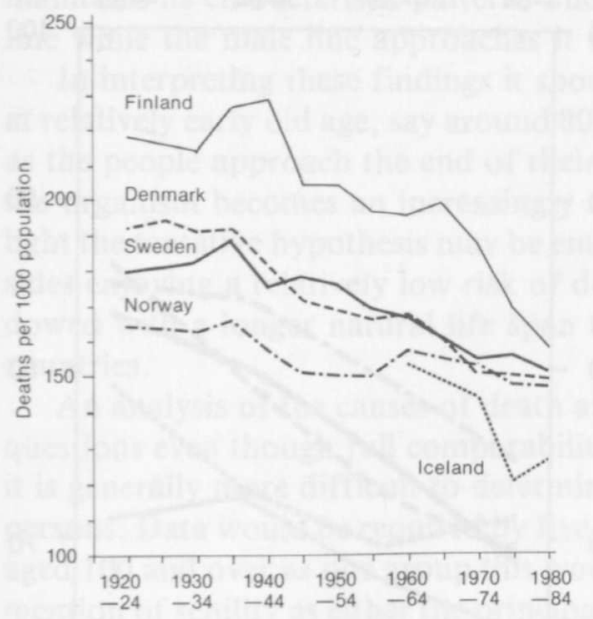

F i g u r e 1 b. Age-standardized death rates, ages 80 and over. Females.

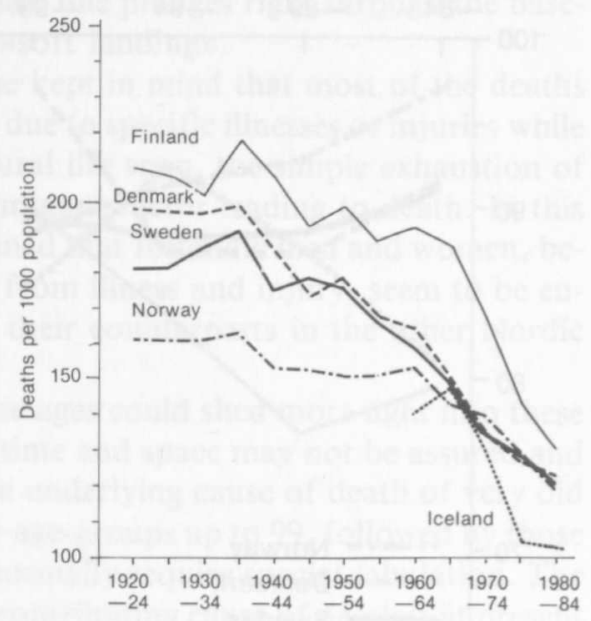

T a b l e 4. Mortality index in $1980-83$ by age, sex and country. $(1950-69=$ $100)$.

\begin{tabular}{|c|c|c|c|c|}
\hline \multirow{2}{*}{$\begin{array}{l}\text { Sex and } \\
\text { country }\end{array}$} & \multicolumn{4}{|c|}{ Age } \\
\hline & $80-84$ & $85-89$ & $90-94$ & $95-99$ \\
\hline \multicolumn{5}{|l|}{ MALE } \\
\hline Denmark & 91.7 & 87.3 & 87.5 & 96.9 \\
\hline Finland & 79.6 & 76.7 & 83.6 & 89.4 \\
\hline Iceland ${ }^{1}$ & 80.7 & 87.6 & 92.1 & 85.0 \\
\hline Norway & 97.1 & 92.7 & 91.3 & 88.2 \\
\hline Sweden & 91.1 & 88.6 & 88.0 & 89.1 \\
\hline \multicolumn{5}{|l|}{ FEMALE } \\
\hline Denmark & 69.4 & 72.6 & 79.3 & 86.2 \\
\hline Finland & 64.7 & 67.7 & 72.5 & 71.1 \\
\hline Iceland ${ }^{1}$ & 71.2 & 69.6 & 73.1 & 78.8 \\
\hline Norway & 74.7 & 79.7 & 84.1 & 85.2 \\
\hline Sweden & 68.7 & 74.6 & 79.9 & 83.2 \\
\hline
\end{tabular}

\footnotetext{
$11961-69=100$
} 
F i g u r e 2. Mortality index in $1980-83$ when $1950-69=100$.

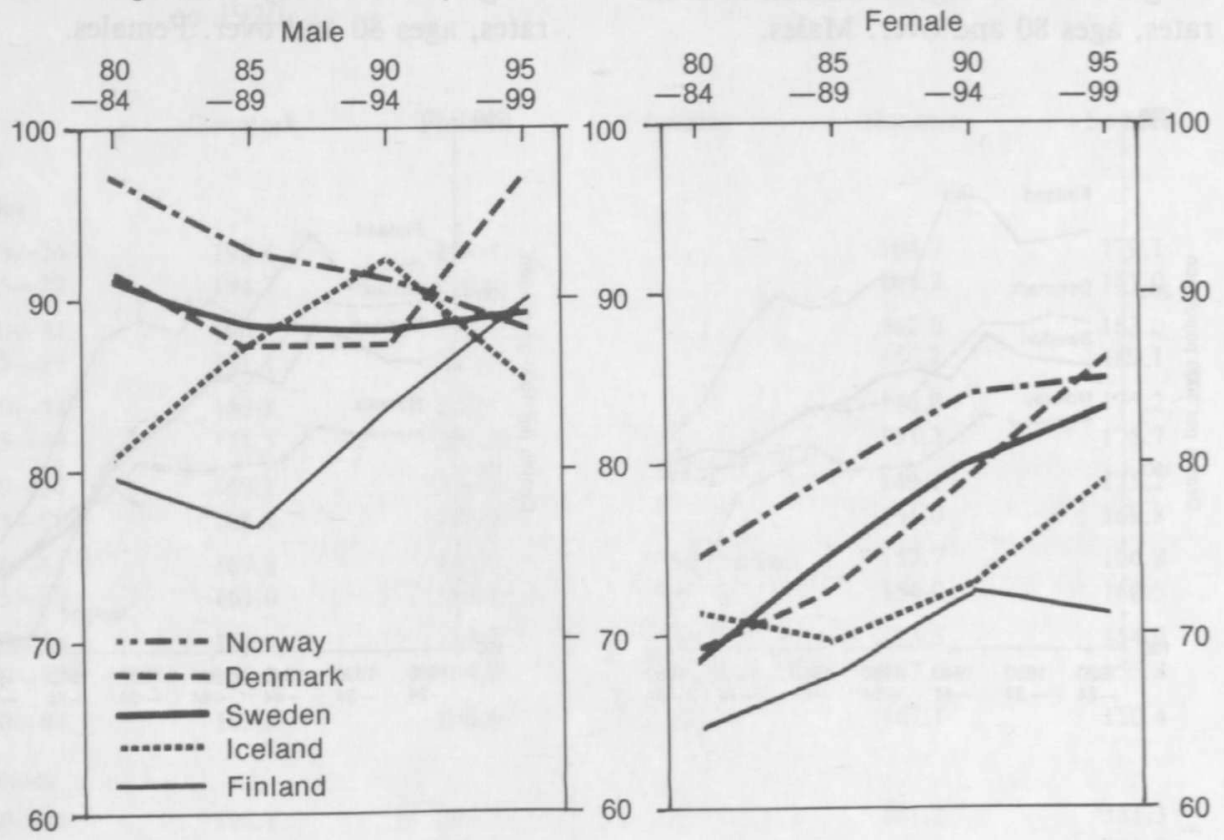

For women the overall decline was largest in Finland, next in Iceland, then roughly equal in Sweden and Denmark and a little smaller but still very considerable in Norway. Most of the countries display a quite uniform profile of greatest declines at lowest ages and smaller ones at the oldest. As an exception, in Finland the decline is quite large also in the age group 95-99 years: 28 percent vs. 14 to 21 percent in the other countries.

The differential development has influenced the age pattern of mortality as is show below.

\section{Age pattern of mortality}

The development of the age patterns of mortality is studied here by four quinquennial age groups in four major periods (three for Iceland), relating them to corresponding Swedish rates which are set equal to 100 . The results in Table 5 are further illustrated in Figures $3 \mathrm{a}$ and $3 \mathrm{~b}$.

The figures of the various periods resemble fans, wider at the younger end and narrower at the other. This indicates a certain convergence as age advances and is to be expected because when an index base rises, it will less likely be exceeded in the same proportion as before. In all post-war periods, with the exception of Norwegian women in 1950-69, the Danish and Norwegian curves are approximately horizontal and thus parallel with the Swedish base, meaning that in all three countries the age pattern of old age mortality is closely similar. The Icelandic curves are not very steady but the female ones do not differ in a major way from horizontal lines and the low values for men of 80-84 may not be very significant. Iceland, therefore, seems also to conform with the Scandinavian age pattern although its levels are much lower. 
Finland presents a sharply contrasting age pattern with very high excess mortality at the younger end and low, if any, excess at the old end. In the recent periods the mortality in Finland approaches the level of the other three major countries but maintains its characteristic pattern. The female line plunges right through the baseline while the male line approaches it in a »soft landing».

In interpreting these findings it should be kept in mind that most of the deaths at relatively early old age, say around 80 , are due to specific illnesses or injuries while as the people approach the end of their natural life span, the simple exhaustion of the organism becomes an increasingly determinant factor leading to death. In this light the tentative hypothesis may be entertained that Icelandic men and women, besides enjoying a relatively low risk of death from illness and injury, seem to be endowed with a longer natural life span than their counterparts in the other Nordic countries.

An analysis of the causes of death at these ages could shed more light into these questions even though full comparability in time and space may not be assured and it is generally more difficult to determine the underlying cause of death of very old persons. Data would be required by five-year age-groups up to 99 , followed by those aged 100 and over as one group this would normally require special tabulation. The mention of senility as either the principal or contributing cause of death is at present not encouraged in medical certification of death and there is therefore little evidence of it in statistics. This may make it difficult to evaluate the part played by the natural length of life in mortality.

$\mathrm{T}$ a b l e 5. Mortality index in Denmark, Finland, Iceland, and Norway by sex, age and period $($ Sweden $=100)$.

\section{Male}

$\begin{array}{lrrrr}\begin{array}{l}\text { Country and } \\ \text { period } \\ \text { Denmark }\end{array} & 80-84 & 85-89 & 90-94 & 95-99 \\ \begin{array}{l}1920-39 \\ 1950-69\end{array} & 108.0 & 104.2 & 102.4 & 95.1 \\ 1970-79 & 96.2 & 98.7 & 98.1 & 89.6 \\ 1980-83 & 101.4 & 97.2 & 97.8 & 97.1 \\ \text { Finland } & & & & 97.4 \\ 1920-39 & 125.3 & 116.9 & 112.6 & 109.3 \\ 1950-69 & 125.4 & 116.7 & 109.2 & 103.1 \\ 1970-79 & 119.1 & 112.0 & 111.0 & 112.1 \\ 1980-83 & 109.7 & 101.0 & 103.8 & 103.4 \\ \text { Iceland } & & & & \\ 1961-69 & 88.4 & 91.8 & 85.5 & 93.9 \\ 1970-79 & 80.3 & 89.8 & 86.2 & 86.1 \\ 1980-83 & 78.4 & 90.7 & 89.6 & 89.6 \\ \text { Norway } & & & & \\ 1920-39 & 89.3 & 89.4 & 90.6 & 92.6 \\ 1950-69 & 91.3 & 90.4 & 92.1 & 93.3 \\ 1970-79 & 97.5 & 95.8 & 97.8 & 97.8 \\ 1980-83 & 97.3 & 94.6 & 95.5 & 92.4\end{array}$

Female

$80-84 \quad 85-89 \quad 90-94 \quad 95-99$

$\begin{array}{rrrr}109.3 & 105.9 & 102.7 & 103.1 \\ 101.4 & 100.8 & 102.1 & 100.7 \\ 97.8 & 99.0 & 101.5 & 100.7 \\ 102.5 & 98.1 & 101.2 & 104.3\end{array}$

$\begin{array}{rrrr}118.3 & 111.1 & 107.8 & 108.8 \\ 122.5 & 119.0 & 115.3 & 108.7 \\ 124.8 & 119.8 & 114.0 & 103.5 \\ 115.5 & 107.9 & 104.6 & 92.9\end{array}$

$\begin{array}{llll}85.5 & 89.7 & 93.6 & 86.8\end{array}$

$\begin{array}{llll}89.2 & 91.5 & 85.6 & 92.0\end{array}$

$\begin{array}{llll}88.7 & 83.7 & 85.6 & 82.3\end{array}$

$\begin{array}{rrrr}85.7 & 86.2 & 88.9 & 89.6 \\ 90.6 & 91.4 & 93.9 & 96.6 \\ 102.5 & 102.8 & 102.9 & 100.3 \\ 99.9 & 97.5 & 98.7 & 98.9\end{array}$


Survival ratios measure mortality from a different angle than the death rates and give relatively greater emphasis to ages in which mortality is high. A long-term survival parameter does not possess the inherent smoothing mechanism of a corresponding mortality parameter and if any link in the chain that produces ${ }_{n} p_{x}$ is weak in the sense of containing few observations, the product may be seriously affected. When during 1970 - 74 only six Icelandic men reached the age 99 and all died before age 100 , the survival ratio for the entire $80-100$ age span became nil. The Finnish values for this parameter in Table 6 are also quite erratic in the earlier years due to the small number of observations.

Survival ratios from 80 to 100 years of age since 1920 are shown for each country in Table 6 and Figures 4a and 4b. The curves for Iceland have been excluded from the figures because of their sharp vacillations and their recent levels which are so high that they would dwarf the other curves. The data illustrate the slow and unsteady improvement in survival until the 1960 s and the accelerating trend since then. Particularly the values for women have risen at an extraordinarily fast pace. In the last two decades alone the chances of an 80-year-old woman to reach age 100 have more than tripled in all Nordic countries and grown sevenfold in Finland. Among men the corresponding chances have increased by factors which range from 1.7 in Denmark to 4.7 in Finland. These findings explain the present rapid growth in the numbers of centenarians and prove that the recent improvement in the survival of octogenarians and nonagenarians is without precedent.

It may be found surprising that in a wide age span such as $80-99$ years, the ranking of countries by survival is not necessarily the reverse of their ranking by mortality. In 1980-83 Finnish women had the highest mortality but a survival ratio which was higher than that of Danish women and almost equal to that of Swedish women. The reason is that the mortality of women in Finland was higher at ages 80-94 but lower at 95-99 than in Denmark and Sweden as shown in Table 5. For the survival ratio it is the older ages with their high probabilities of dying that matter most.

\section{Sex differentials in old age mortality}

Sex differentials of mortality are here measured as the level of male mortality when female mortality is equal to 100 . We shall call this the sex ratio of mortality.

Table 7 and Figure 5 show the development of the overall sex ratio in the entire $80-99$ age group since 1920. The ratio for Iceland is not shown in the figure because with its strong swings it would make the figure difficult to read; giving allowance for unsteadiness, it is not significantly different from the others. The ratios remain on the same general level until the 1960 s when they begin to increase very fast. Since then, in 20 years, the male excess rose form roughly 10 percent to about 30 percent.

Although in Finland the difference between the general mortality of males and females is perhaps the highest in the world (life expectancy at birth 78.8 years for females and 70.4 for males in 1984), at ages above 80 years it is not particularly high and in 1980 - 83 was actually lower than in the other Nordic countries.

Sex ratios of mortality are shown by age group in Table 8 and illustrated in Figure 6 in which we have placed Denmark, Norway, and Sweden side by side to demonstrate the similarity of their ratios. Up to and including the $1950-69$ period the male excess mortality was relatively uniform in all the countries and showed only a slight tendency to decline towards the oldest ages; an exception was the small female excess mortality at ages 95-99 in Denmark. In the 1970s and 1980s, the epoch of rapid 
mortality decline, the relative male excess grew in an explosive manner and in Denmark, Norway, and Sweden took a highly differentiated form by age: more than 45 percent at $80-84$ and only between 10 and 17 percent at $95-99$. In Iceland which is not shown in the figure, a tendency towards lower ratios at the oldest ages can also be observed.

In Finland the rise of the sex ratio was a little less remarkable than in the other three major countries and followed a quite different age-pattern. The rise of the ratio at ages below 90 years was more moderate than in the other countries, about equal at ages 90-94 and much faster above 95 , resulting in a distinct $U$-curve which underlines the exceptionally low mortality of the oldest Finnish women.

T a b l e 6. Survivors to age 100 years out of 100,000 persons of age 80 .

$\begin{array}{lrrrrrrrrrr}\text { Year } & \begin{array}{r}\text { Den- } \\ \text { mark }\end{array} & \begin{array}{r}\text { Fin- } \\ \text { land }\end{array} & \begin{array}{c}\text { Ice- } \\ \text { land }\end{array} & \begin{array}{l}\text { Nor- } \\ \text { way }\end{array} & \begin{array}{r}\text { Swe- } \\ \text { den }\end{array} & \begin{array}{r}\text { Den- } \\ \text { mark }\end{array} & \begin{array}{r}\text { Fin- } \\ \text { land }\end{array} & \begin{array}{r}\text { Ice- } \\ \text { land }\end{array} & \begin{array}{r}\text { Nor- } \\ \text { way }\end{array} & \begin{array}{r}\text { Swe- } \\ \text { den }\end{array} \\ 1920-24 & 173 & 55 & \ldots & 299 & 151 & 110 & 118 & \ldots & 465 & 219 \\ 1925-29 & 183 & 128 & \ldots & 244 & 198 & 195 & 105 & \ldots & 493 & 312 \\ 1930-34 & 136 & 38 & \ldots & 341 & 152 & 168 & 165 & \ldots & 473 & 181 \\ 1935-39 & 158 & 33 & \ldots & 328 & 116 & 141 & 41 & \ldots & 489 & 171 \\ 1940-44 & 344 & 12 & \ldots & 444 & 159 & 247 & 70 & \ldots & 545 & 334 \\ 1945-49 & 417 & 111 & \ldots & 383 & 154 & 393 & 190 & \ldots & 610 & 248 \\ 1950-54 & 392 & 74 & \ldots & 498 & 192 & 284 & 185 & \ldots & 660 & 198 \\ 1955-59 & 481 & 132 & \ldots & 342 & 219 & 426 & 192 & \ldots & 631 & 404 \\ 1960-64 & 368 & 79 & 276 & 377 & 210 & 420 & 219 & 1159 & 522 & 565 \\ 1965-69 & 368 & 186 & 495 & 468 & 347 & 661 & 208 & 767 & 826 & 733 \\ 1970-74 & 580 & 141 & - & 515 & 457 & 1123 & 513 & 1287 & 937 & 1111 \\ 1975-79 & 504 & 281 & 481 & 552 & 445 & 1260 & 986 & 4392 & 1312 & 1294 \\ 1980-83 & 622 & 375 & 1093 & 763 & 533 & 1474 & 1587 & 3631 & 1776 & 1636 \\ 1961-64 & & & & & & & & & & \end{array}$

F i g u r e 4 a. Survivors to age 100 years out of 1,000 men of age 80 .

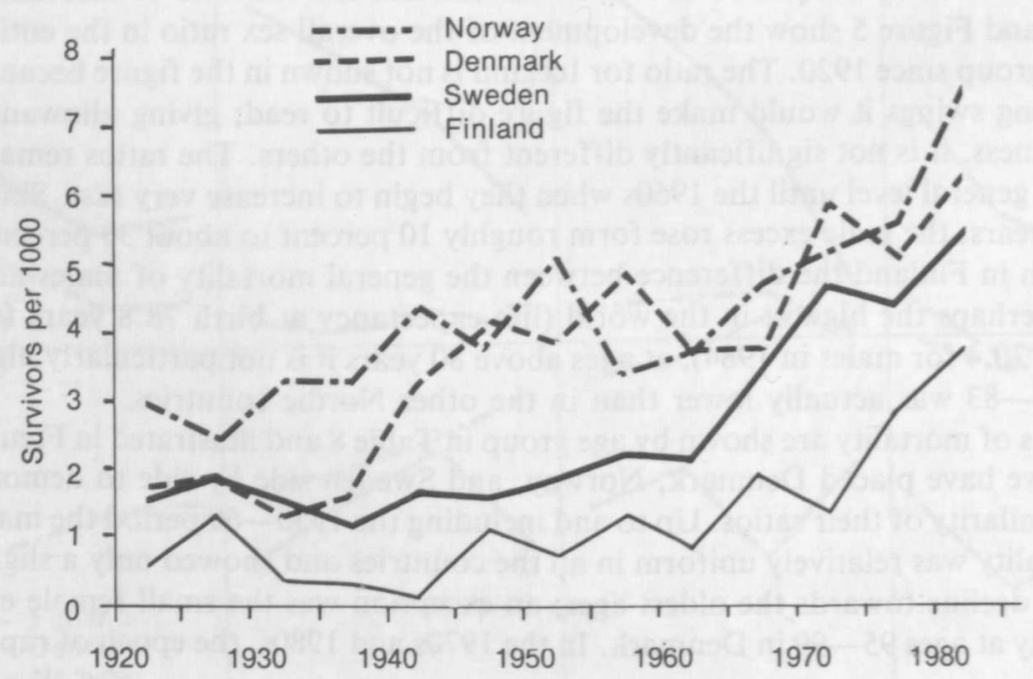


F i g u r e 4 b. Survivors to age 100 years out of 1,000 women of age 80 .

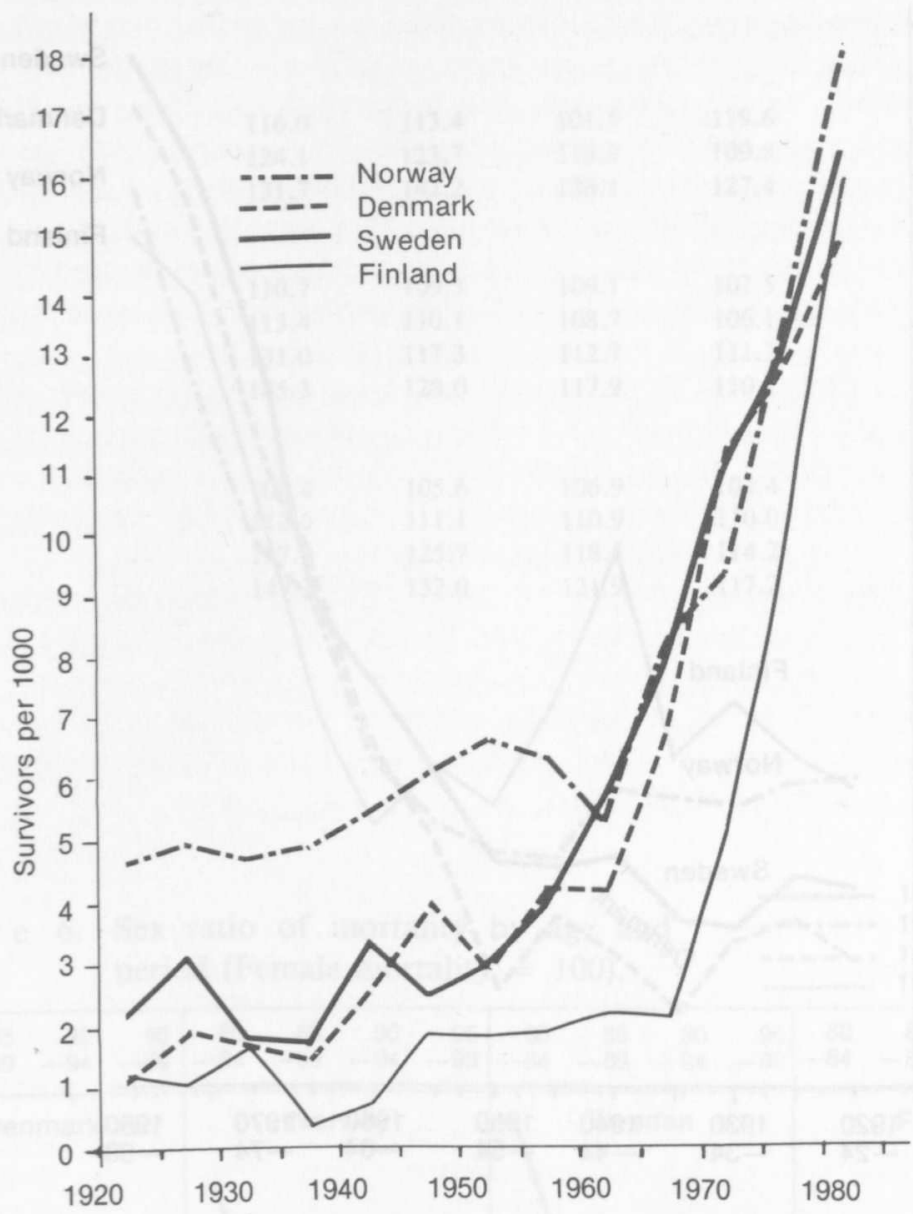

$\mathrm{T} \mathrm{a} \mathrm{b} \mathrm{l} \mathrm{e} \mathrm{7.} \mathrm{Sex} \mathrm{ratio} \mathrm{of} \mathrm{mortality} \mathrm{at} \mathrm{ages} \mathrm{80-99.} \mathrm{Age-standardized.} \mathrm{(Female} \mathrm{mor-}$ tality $=100$ )

$\begin{array}{lccccc}\text { Year } & \text { Denmark } & \text { Finland } & \text { Iceland } & \text { Norway } & \text { Sweden } \\ 1920-24 & 104.1 & 109.8 & \ldots & 110.8 & 106.6 \\ 1925-29 & 105.5 & 110.8 & \ldots & 109.9 & 106.9 \\ 1930-34 & 104.8 & 112.6 & \ldots & 109.2 & 105.2 \\ 1935-39 & 102.5 & 110.8 & \ldots & 109.4 & 105.6 \\ 1940-44 & 104.3 & 117.3 & \ldots & 110.0 & 107.6 \\ 1945-49 & 105.6 & 112.6 & \ldots & 107.4 & 107.2 \\ 1950-54 & 103.3 & 109.2 & \ldots & 107.7 & 107.4 \\ 1955-59 & 108.0 & 110.5 & \ldots & 108.6 & 110.4 \\ 1960-64 & 111.0 & 108.5 & 115.9^{1} & 110.6 & 113.2 \\ 1965-69 & 116.4 & 112.4 & 108.4 & 115.7 & 115.8 \\ 1970-74 & 121.4 & 119.4 & 118.3 & 117.9 & 124.2 \\ 1975-79 & 128.2 & 126.0 & 125.5 & 123.2 & 130.4 \\ 1980-83 & 132.4 & 128.0 & 134.0 & 129.8 & 134.0\end{array}$


F i g u r e 5. Sex ratio of mortality at ages 80-99 years, standardized for age. (Female mortality $=100$ )

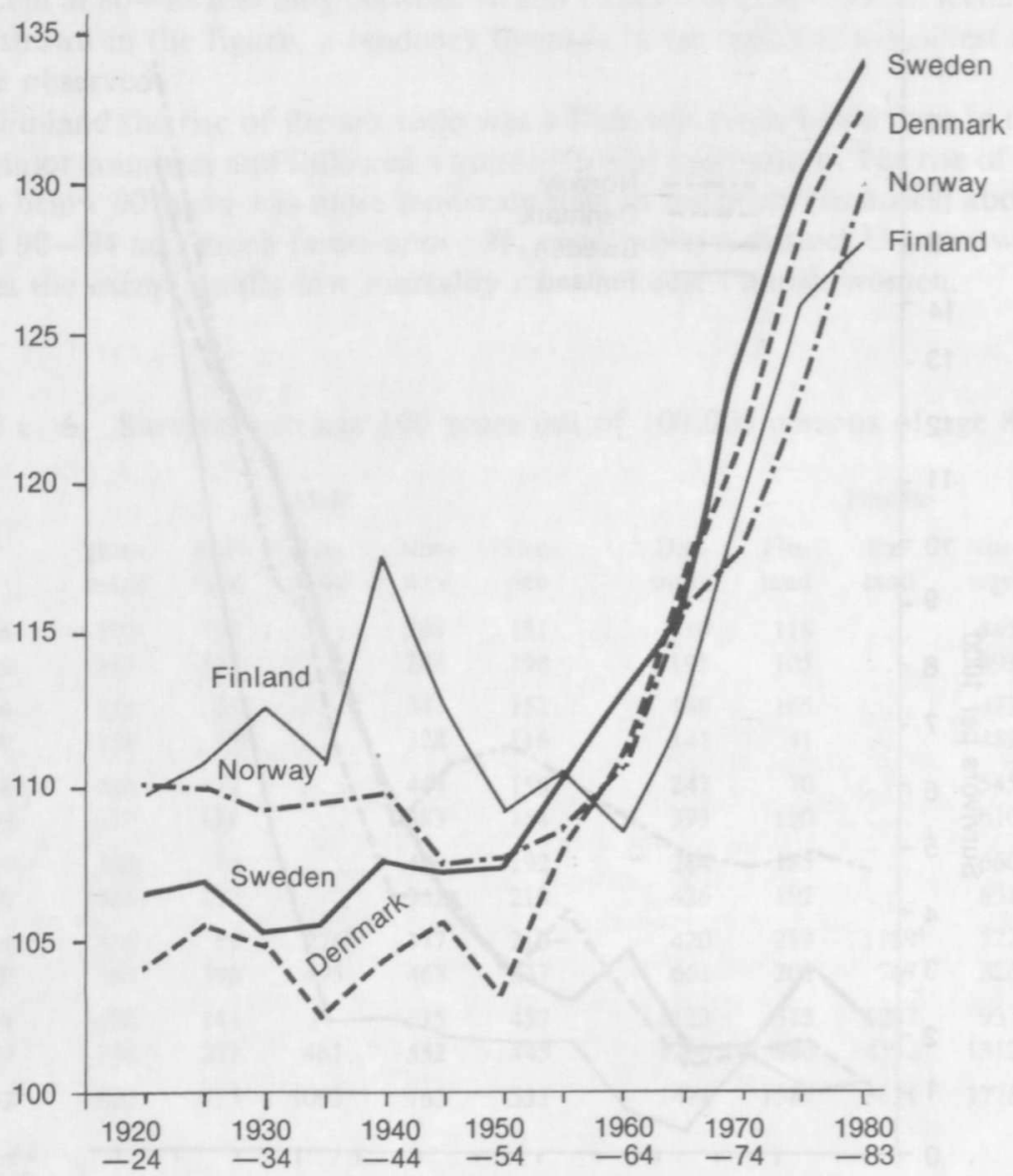

T a b l e 8 . Sex ratio of mortality by age, country, and period.

Age

Country and period

Denmark

$1920-39$

$1950-69$

$1970-79$

1980-83

Finland

1920-39

1950-69

1970-79

1980-83
112.3

115.2

131.5

141.2
110.5

108.9

117.3

118.2
103.8

111.7

125.9

134.0

106.5

114.3

117.9

111.8

104.8

115.2

120.7
Total

80-99

104.2

109.4

125.0

132.4

111.0

110.1

122.4

128.0 
Age

Country and period $80-84$

$85-89$

$90-94$

95-99

Total

80-99

Iceland

1961-69

116.0

113.4

101.5

119.6

112.1

1970-79

124.1

123.7

118.9

109.8

121.5

1980-83

131.7

142.2

128.1

127.4

Norway

1920-39

110.7

109.3

109.1

107.5

1950-69

113.4

110.1

108.7

106.1

131.0

117.3

112.7

111.3

$1980-83$

145.3

128.0

117.9

110.1

Sweden

1920-39

106.4

105.6

106.9

104.4

112.6

111.1

110.9

110.0

1970-79

137.9

125.7

118.5

114.2

134.0

1980-83

149.2

132.0

121.9

117.2

109.6

110.6

120.4

129.8

106.1

111.5

127.2

134.0

Fig u r e 6. Sex ratio of mortality by age and
period (Female mortality $=100$ ).

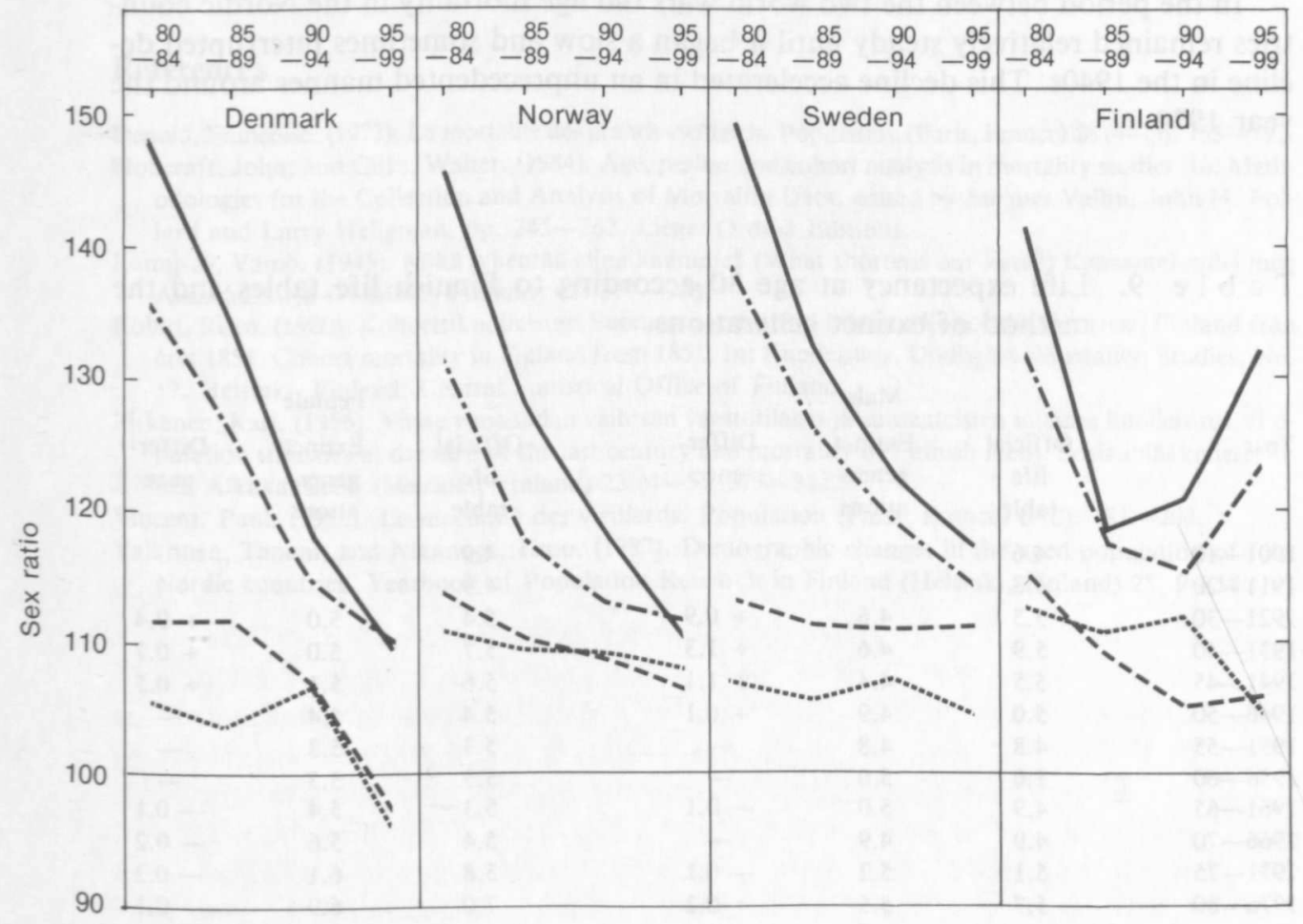




\section{A remark on life tables}

The inaccurate population figures in the decades prior to the causes of 1950 in Finland had a considerable effect on some demographic indicators calculated at that time for the oldest age groups. According to official life tables, the life expectancy at age 80 , shown in Table 9, apparently rose in the 1920 s to a higher level from where it dropped again in the 1946 - 50 period when the 1950 census was used as the benchmark. The life expectancies calculated by the method of extinct generations do not show any such rise and fall, in stead they display a smooth trend, slowly rising for women, nearly stationary for men until a rapid increase began around 1970. It may be concluded that the official life tables for the period 1921-45 were too favorable for old ages.

The smaller differences in later years may be due to the fact that prior to the 1976-80 life table, the probabilities of dying at ages above 85 years were estimated mathematically and thus possibly incorrect. The fact that the method of extinct generations does not strictly follow quinquennial periods but has an overlap in years ending in 0 or 5 , may also have a marginal effect.

If the discrepancy in the population base is limited to ages 80 and over, it has only a minor effect on the estimated total length of life. An error of 1.3 years for men and 0.7 for women in the life expectancy at age 80 which probably occurred in 1931-40 life table would increase the calculated life expectancy at birth of either sex by less than 0.2 years. However, it is likely that the population estimates were too high also at ages below 80 years.

\section{Conclusions}

In the period between the two world wars old age mortality in the Nordic countries remained relatively steady until it began a slow and sometimes interrupted decline in the 1940s. This decline accelerated in an unprecedented manner around the year 1970 .

T a b l e 9. Life expectancy at age 80 according to Finnish life tables and the method of extinct generations.

$\begin{array}{lcccccc}\text { Year } & \begin{array}{c}\text { Male } \\ \text { Official } \\ \text { life } \\ \text { table }\end{array} & \begin{array}{c}\text { Extinct } \\ \text { gener- } \\ \text { ations }\end{array} & \begin{array}{c}\text { Differ- } \\ \text { ence }\end{array} & \begin{array}{c}\text { Female } \\ \text { Official } \\ \text { life } \\ \text { table }\end{array} & \begin{array}{c}\text { Extinct } \\ \text { gener- } \\ \text { ations }\end{array} & \begin{array}{c}\text { Differ- } \\ \text { ence }\end{array} \\ 1901-10 & 4.6 & & & 4.9 & & \\ 1911-20 & 4.8 & & & 4.9 & & \\ 1921-30 & 5.5 & 4.6 & +0.9 & 5.4 & 5.0 & +0.4 \\ 1931-40 & 5.9 & 4.6 & +1.3 & 5.7 & 5.0 & +0.7 \\ 1941-45 & 5.5 & 4.4 & +1.1 & 5.6 & 5.1 & +0.5 \\ 1946-50 & 5.0 & 4.9 & +0.1 & 5.4 & 5.4 & - \\ 1951-55 & 4.8 & 4.8 & - & 5.3 & 5.3 & - \\ 1956-60 & 5.0 & 5.0 & - & 5.5 & 5.5 & - \\ 1961-65 & 4.9 & 5.0 & -0.1 & 5.3 & 5.4 & -0.1 \\ 1966-70 & 4.9 & 4.9 & - & 5.4 & 5.6 & -0.2 \\ 1971-75 & 5.1 & 5.2 & -0.1 & 5.8 & 6.1 & -0.3 \\ 1976-80 & 5.7 & 5.5 & +0.2 & 7.0 & 6.9 & +0.1\end{array}$


In the 1920s Norway had the lowest rates, followed by Sweden, Denmark, and Finland, each on its own distinct level. Gradually over the next decades the Norwegian, Swedish, and Danish rates converged and in the last decade and a half the Finnish rates fell enough to almost catch up with the others. Throughout the period for which we have data for Iceland, mortality has been significantly lower for both sexes than in the other countries and has maintained its lead.

The recent rapid decline has extended even to the very oldest ages. Both sexes have benefited from this decline but women more than men. In this process the chances of surviving from age 80 to 100 have been multiplied by several times and, as a consequence, the number of centenarians is rapidly rising.

Denmark, Norway, and Sweden have, between them, a remarkably similar agepattern of mortality and Iceland also has a similar one, though on a lower level. Finland is different in that at the younger end of the 80-99 year age-span mortality is much higher than in the other countries but towards the older end less so.

The usual male excess mortality is generally less pronounced at the ages here examined than among the young and the middle-aged. In the Nordic countries it fluctuated on the 5 to 10 percent level until it suddenly rose to 30 percent and over during the recent mortality decline, suggesting that factors earlier associated only with younger ages have extended their influence upwards on the age scale.

The findings seem to justify the view that mortality at very old age is organically linked to that among the elderly in general and responds to new impacts in a similar manner though perhaps more mutedly. If this is the case, it follows that persons who now pass the 80 -year mark, not only survive longer but keep in better health than earlier generations.

\section{References}

Depoid, Françoise. (1973). La mortalité des grands vieillards. Population (Paris, France) 28 (4-5): 755 - 792.

Hobcraft, John; and Gilks, Walter. (1984). Age, period and cohort analysis in mortality studies. In: Methodologies for the Collection and Analysis of Mortality Data, edited by Jacques Vallin, John H. Pollard and Larry Heligman, pp. 245-262. Liège: Ordina Editions.

Kannisto, Väinö. (1945). Mikä lyhentää elinaikaamme? (What shortens our lives?) Kansantaloudellinen Aikakauskirja (Helsinki, Finland) 41: 377-383.

Kolari, Risto. (1980). Kohorttikuolleisuus Suomessa v:sta 1851 lähtien. Kohortdödligheten i Finland från året 1851. Cohort mortality in Finland from 1851. In: Kuolleisuus. Dödlighet. Mortality. Studies, No. 57. Helsinki, Finland: Central Statistical Office of Finland.

Pitkänen, Kari. (1986). Viime vuosisadan vaihteen väestötilasto ja suomalaisten miesten kuolleisuus. (Population statistics at the turn of the last century and mortality of Finnish men). Sosiaalilääketieteellinen Aikakauslehti (Helsinki, Finland) 23 (4-5): 375-382.

Vincent, Paul. (1951). La mortalité des vieillards. Population (Paris, France) 6 (2): 181-204.

Valkonen, Tapani; and Nikander, Timo. (1987). Demographic changes in the aged population of four Nordic countries. Yearbook of Population Research in Finland (Helsinki, Finland) 25: 9-18. 